\section{Assessing the Educational Needs of Canadians with Systemic Sclerosis}

\section{To the Editor:}

Changes in appearance, significant morbidity, and the absence of disease-modifying therapies may lead to psychosocial issues in patients with systemic sclerosis $(\mathrm{SSc})^{1,2,3,4}$. Limited education may contribute to poor medication adherence ${ }^{5}$. Education of patients could potentially mediate some of these outcomes ${ }^{2,6}$ because patient education in rheumatic disease improves self-efficacy and self-management ${ }^{7,8}$. An Educational Needs Assessment Tool (ENAT) was developed to assess the perceived educational needs of people with rheumatic disease ${ }^{9}$, and has been validated in patients with $\mathrm{SSc}^{10}$. We used the ENAT to survey a sample of Canadians with SSc to understand their educational need(s) to inform educational initiatives and future research. This project was not deemed to require ethics approval by the Hamilton Integrated Research Ethics Board, and thus written consent was not required.

The ENAT questionnaire was posted on the Scleroderma Society of Ontario and Scleroderma Society of Canada social media accounts in August 2017. Patients from 2 clinics were also provided with the online survey link. All data were self-reported. Participants were asked the dichotomous question, "Do you want education about anything to help you deal with your scleroderma?", an open-ended question about desired educational needs, and were asked to describe the extent to which they want to know about their SSc (4-point Likert scale). Seven domains of perceived needs (4-7 questions each) were assessed. Responses were given on a 5-point Likert scale $(0=$ not at all important; $4=$ extremely important $)$. A total score was derived for each domain and overall (maximum $156=$ high need). Scores were then converted into a percent of maximum score ${ }^{11}$. Linear regression analyses determined the association between patient characteristics and ENAT scores. Stata for Mac (version 13.2) was used for data analysis.

Characteristics of the 49 patients are summarized in Table 1. The mean (SD) total ENAT score was 111 (34), representing $71.2 \%$ of the maximum score (Table 2). Highest needs were in the domains of information about SSc, self-help, and treatments. Desire for disease-related information was associated with total ENAT score $(\beta=25.56 ; \mathrm{p}<0.001)$. There was no association between total ENAT score and age, duration of disease, or age at school completion $(\mathrm{p}>0.05)$. Open-ended responses identified needs related to organ involvement $(n=10)$, pain $(n=8)$, research and/or emerging treatments $(n=8)$, disease effect on mental health and daily function $(n=6)$, Raynaud phenomenon $(n=4)$, complementary and alternative management $(n=3)$, and enhancing interactions with specialist physicians $(n=3)$.

Our results demonstrate high overall educational needs, indicated by relatively high mean total ENAT score, with greatest needs in self-help, disease information, and treatment. As expected, those desiring more disease-related information had higher overall educational needs. Open-ended responses suggest a need for more information regarding research initiatives, alternative treatments, and the management of disease

Table 1. Participant characteristics $(n=49)$.

\begin{tabular}{lcccc}
\hline Characteristics & $\begin{array}{c}\text { Mean } \\
\text { or N }\end{array}$ & $\begin{array}{c} \pm \text { SD } \\
\text { or } \%\end{array}$ & Median & Range \\
\hline Females & 46 & 92 & - & - \\
Age, yrs & 52.2 & \pm 10.9 & 53 & $31-73$ \\
Duration since diagnosis, yrs & 10.5 & \pm 9.5 & 8 & $0-37$ \\
Age at education completion, yrs & 19.9 & \pm 3.6 & 18 & $16-32$ \\
Want "education about anything to help you deal & 39 & 80 & - & - \\
$\quad$ with your scleroderma" & 36 & 92.3 & - & - \\
I want to know "lots" & 0 & 0 & - & - \\
I want to know "everything" & 0 & 7.7 & - & - \\
I want "to know some things" & 3 & 0 & - & - \\
I want to know "nothing" & 0 & & & \\
\hline
\end{tabular}

Table 2. Education Needs Assessment Tool (ENAT) scores in each of the 7 domains $(n=49)$.

\begin{tabular}{lcccc}
\hline Domain & Mean (SD) & SD & Range & $\begin{array}{c}\text { Mean } \\
\text { (\% of max)* }\end{array}$ \\
\hline Managing pain (0-24) & 15.7 & 5.8 & $2.7-24$ & 65.4 \\
Movement (0-20) & 12.7 & 5.9 & $0-20$ & 63.5 \\
Feelings (0-16) & 10.9 & 5.0 & $0-16$ & 68.1 \\
Scleroderma (0-28) & 21.9 & 6.0 & $6.2-28$ & 78.2 \\
Treatments (0-28) & 20.2 & 7.4 & $0-28$ & 72.1 \\
Self-help (0-24) & 18.4 & 5.5 & $4.3-24$ & 76.7 \\
Support (0-16) & 11.2 & 4.7 & $0-16$ & 70.0 \\
Total ENAT score (0-156) & 111.0 & 34.3 & $15-156$ & 71.2 \\
\hline
\end{tabular}

* Greatest needs as determined by the maximum possible ENAT score ${ }^{11}$.

sequela. Our data generally support results from previous studies $6,11,12,13$, including the presence of significant psychosocial needs ${ }^{12,13}$. Although not explored in detail here, addressing psychosocial needs should be prioritized in future initiatives.

We collected minimal patient characteristics data (Table 1), which did not allow us to adequately explore potential differences between those who did versus did not want information related to SSc. It is unclear whether those with low education needs have sufficient disease-related knowledge or whether they are different demographically (socioeconomic status, access to care, health literacy) from those with high needs. Personal health-related outcomes (i.e., disease activity) may also play a role in educational needs, as previously shown in other rheumatologic conditions ${ }^{14}$. Thus, an important next step would be to explore characteristics of patients who do not want disease-related education and whether perceived needs may be linked to disease outcomes and healthcare access.

Our data relied on self-report for diagnosis of SSc and were limited to a convenience sample of participants who had access to the Internet and social media. While we had 49 respondents, a larger sample compared to similar studies $^{6,11,12}$, we are unable to comment on the generalizability of our results. A study investigating Internet use among patients with SSc found widespread use and a preference for disease-related information over nonmedical information (e.g., lifestyle modification) ${ }^{15}$. Another study demonstrated patient interest in multidisciplinary services and information provided by rheumatologists ${ }^{13}$. Future research should explore the optimal medium for providing information to patients, needs of non-Internet users, and methods of optimizing the delivery of online education.

The variability of our patient population (Table 1) and their educational needs (Table 2) suggests that a multifactorial approach to addressing patient needs is required. To address a patient-directed agenda and the heterogeneity in patients and needs, partnerships between patients, patient groups, clinicians, and researchers should be fostered. Such partnerships would facilitate the development of informational materials and appropriate, effective, and accessible methods of information dissemination. In so doing, we would optimize information and delivery to meet the needs of patients in this study, and also those who are more difficult to reach or do not use the Internet.

\section{ACKNOWLEDGMENT}

Many thanks to the Scleroderma Society of Ontario and the Scleroderma Society of Canada for distribution of the survey.

TERESA SEMALULU, MD, MPH, Department of Medicine, Internal Medicine Training Program; KAREN A. BEATTIE, PhD, Associate Professor, Department of Medicine, Division of Rheumatology; MAGGIE J. LARCHÉ, MRCP(UK), PhD, Associate Professor, Department of Medicine, Divisions of Rheumatology and Clinical Immunology and Allergy, McMaster University, Hamilton, Ontario, Canada. Address correspondence to Dr. T. Semalulu, Department of Medicine, Internal Medicine Training Program, McMaster University Medical Centre, Room 1K11, 
1200 Main St. West, Hamilton, Ontario L8N 3Z5, Canada.

E-mail: teresa.semalulu@medportal.ca

\section{REFERENCES}

1. Joachim G, Acorn S. Life with a rare chronic disease: The scleroderma experience. J Adv Nurs 2003;42:598-606.

2. Mura G, Bhat KM, Pisano A, Licci G, Carta M. Psychiatric symptoms and quality of life in systemic sclerosis. Clin Pract Epidemiol Ment Health 2012;8:30-5.

3. Thombs BD, Taillefer SS, Hudson M, Baron M. Depression in patients with systemic sclerosis: A systematic review of the evidence. Arthritis Rheum 2007;57:1089-97.

4. Nguyen C, Ranque B, Baubet T, Berezne A, Mestre-Stanislas C, Rannou F, et al; Groupe Français de Recherche sur la Sclérodermie. Clinical, functional and health-related quality of life correlates of clinically significant symptoms of anxiety and depression in patients with systemic sclerosis: a cross-sectional survey. PLoS One 2014;9:e90484.

5. Betegne AL, Gauchet A, Lehmann A, Grange L, Roustit M, Baudrant M, et al. Why do patients with chronic inflammatory rheumatic diseases discontinue their biologics? An assessment of patients' adherence using a self-report questionnaire. J Rheumatol 2016;43:724-30

6. Kwakkenbos L, Bluyssen SJ, Vonk MC, van Helmond AF, van den Ende $\mathrm{CH}$, van den Hoogen $\mathrm{FH}$, et al. Addressing patient health care demands in systemic sclerosis: Pre-post assessment of a psycho-educational group programme. Clin Exp Rheumatol 2011;29:S60-5.

7. Taal E, Rasker JJ, Wiegman O. Patient education and self-management in the rheumatic diseases: a self-efficacy approach. Arthritis Care Res 1996;9:229-38.

8. Ndosi M, Johnson D, Young T, Hardware B, Hill J, Hale C, et al. Effects of needs-based patient education on self-efficacy and health outcomes in people with rheumatoid arthritis: a multicentre, single blind, randomised controlled trial. Ann Rheum Dis 2016;

75:1126-32

9. Hardware B, Lacey EA, Shewan J. Towards the development of a tool to assess educational needs in patients with arthritis. Clin Eff Nurs 2004;8:111-7.

10. Ndosi M, Bremander A, Hamnes B, Horton M, Kukkurainen ML, Machado P, et al. Validation of the educational needs assessment tool as a generic instrument for rheumatic diseases in seven European countries. Ann Rheum Dis 2014;73:2122-9.

11. Schouffoer AA, Ndosi ME, Vliet Vlieland TP, Meesters JJ. The educational needs of people with systemic sclerosis: A cross-sectional study using the Dutch version of the Educational Needs Assessment Tool (D-ENAT). Rheumatol Int 2016;36:289-94.

12. Rubenzik TT, Derk CT. Unmet patient needs in systemic sclerosis. J Clin Rheumatol 2009;15:106-10.

13. Schouffoer AA, Zirkzee EJ, Henquet SM, Caljouw MA, Steup-Beekman GM, van Laar JM, et al. Needs and preferences regarding health care delivery as perceived by patients with systemic sclerosis. Clin Rheumatol 2011;30:815-24.

14. Dragoi RG, Ndosi M, Sadlonova M, Hill J, Duer M, Graninger W, et al. Patient education, disease activity and physical function: can we be more targeted? A cross sectional study among people with rheumatoid arthritis, psoriatic arthritis and hand osteoarthritis. Arthritis Res Ther 2013;15:R156.

15. van de Vaart R, Repping-Wuts H, Drossaert CH, Taal E, Knaapen-Hans HK, van de Laar MA. Need for online information and support of patients with systemic sclerosis. Arthritis Care Res 2013;65:594-600

First Release April 1 2019; J Rheumatol 2019;46:6; doi:10.3899/jrheum.180554 